Research Article

\title{
Properties of Degraded Waste PET-Modified Styrene-Acrylic Emulsions for Cement Slurry Materials
}

\author{
Jinxi Dou $\mathbb{D}^{1,2}$ Guijin Zhang, ${ }^{1,2}$ Sufang Li $\mathbb{D}^{3},{ }^{3}$ Chengyu Tian, ${ }^{4}$ Cunlu Ji, ${ }^{3}$ and Cong Zhang ${ }^{5}$ \\ ${ }^{1}$ School of Hydraulic Engineering, Changsha University of Science \& Technology, Changsha 410114, Hunan, China \\ ${ }^{2}$ Key Laboratory of Water-Sediment Sciences and Water Disaster Prevention of Hunan Province, Changsha 410114, China \\ ${ }^{3}$ College of Chemistry and Chemical Engineering, Hunan University, Changsha 410114, Hunan, China \\ ${ }^{4}$ Sinohydro Bureau 8 Co., Ltd., Changsha 410114, Hunan, China \\ ${ }^{5}$ School of Civil Engineering, Central South University, Changsha 410114, Hunan, China \\ Correspondence should be addressed to Sufang Li; hnlis@163.com
}

Received 19 July 2019; Revised 9 September 2019; Accepted 5 October 2019; Published 19 December 2019

Academic Editor: José Aguiar

Copyright (c) 2019 Jinxi Dou et al. This is an open access article distributed under the Creative Commons Attribution License, which permits unrestricted use, distribution, and reproduction in any medium, provided the original work is properly cited.

\begin{abstract}
The properties of a modified cement slurry based on degraded waste PET-modified styrene-acrylic emulsions are studied. The effects of the modified styrene-acrylic emulsion on water consumption, setting time, retarding effect, water retention, impermeability, and mechanical properties of the cement slurry are comprehensively studied. The results show that the modified styrene-acrylic emulsion has the following impacts on the cement slurry: it significantly reduces the water consumption required to reach a standard consistency, slows down the initial and final setting times, and greatly improves the water retention rate and water reduction rate. When the content of modified styrene-acrylic emulsion is $7.5 \%$, the water reduction rate is $36 \%$ and the water retention rate is $97 \%$. The solidified cement slurry with a modified styrene-acrylic emulsion content less than $7.5 \%$ has lower permeability and higher flexural strength than a common cement slurry. The compressive strength is reduced but can still reach required values. According to SEM observations, the modified styrene-acrylic emulsion can enhance the bonding strength between the cement particles, reduce the porosity of the structure, and improve the performance of cement-based composites.
\end{abstract}

\section{Introduction}

Polyethylene terephthalate (PET) is a thermoplastic polymer with excellent performance [1]. Almost all soft drink and drinking water bottles produced in the world are made of PET polyesters, and the annual output in China alone is more than 10 million tons. Recycling of PET waste materials helps reduce environmental pollution. At present, there are mainly two kinds of waste PET polyester utilization methods $[2,3]$. One is the physical method, where waste PET is recycled through separation, crushing, washing, and drying treatments to achieve secondary utilization. The physical process is simple and inexpensive, and the properties of various recycled plastics are greatly reduced. However, PET polyesters treated by physical methods still contain a large number of impurities, which greatly limits their application areas. Additional techniques involve chemical methods, including alcoholysis, hydrolysis, ammonolysis, and amination [4-8].

Specifically, waste PET can be degraded by diols to obtain unsaturated low molecular weight polyesters. The two end groups of unsaturated low molecular weight polyesters are hydroxyl groups, which have many potential uses due to their active properties and their ability to react with other products. Therefore, this material has been widely studied by scholars. Farahat and Nikles [9] synthesized a modified unsaturated polyester (UPR) by diethylene glycol (DEG) and PET reactions with different molar ratios and degradation products. Khan and Chandra [10] proposed a method to prepare coatings from waste PET by alcoholysis of waste PET with glycerol or monoglyceride to degrade the polyester and then added benzanhydride or benzanhydride and fatty acid into the prepared mixture to produce modified alkyd resin. Saravari et al. [11] synthesized a new carbamate- 
modified paint with PET degradation products. This paint had good hardness and adhesion and excellent water and acid resistance. Tawfik [12] prepared unsaturated polyester resin with recycled PET, which was further emulsified with water to make a polyester emulsion with $50 \%$ water content. This emulsion can be used for casting crafts or making large relief products. Tawfik and Eskander [13] degraded PET polyester with propylene glycol to produce unsaturated polyester through reaction with acetic anhydride and fatty acid. The unsaturated polyester can react with styrene to produce a modified polyester. The polyester is used in concrete, and the obtained polyester concrete has a low water absorption rate, small voids, low surface porosity, and good chemical corrosion resistance in seawater and groundwater. Full utilization of waste PET polyester degradation products not only solves the problem of environmental pollution but also saves resources.

As an important intermediate product or raw material, Styrofoam emulsions have attracted wide attention due to their advantages of nontoxicity, tastelessness, nonflammability, decreased pollution, weathering resistance, chemical corrosion resistance, and adjustable gloss [14, 15]. Although styrene-acrylic emulsions have many advantages, they also have many problems that cannot be ignored [16-22]: (1) when methyl methacrylate is completely or partially replaced by styrene, hydrogen atoms on the tertiary carbon atoms directly connected to the benzene ring are easily oxidized due to the induction effect of a benzene ring on electrons, leading to poor weatherability; (2) the stability of $\mathrm{Ca}^{2+}$ is low, the minimum film-forming temperature is high, and the rigid benzene ring can improve the hardness of the emulsion but also reduce the film-forming performance of the emulsion; and (3) the styrene-acrylic emulsion becomes brittle at low temperatures and becomes thick at high temperatures. To overcome these shortcomings, technologists worldwide have explored the modification of styreneacrylic emulsions. Common modified substances mainly include polyurethanes [23-25], organic silicon compounds $[26,27]$, organic fluorine compounds [28], epoxy resins $[20,29,30]$, and other functional monomers [31]. Ji et al. studied the use of a degraded waste PET-modified styreneacrylic emulsion and learned that 2-hydroxyethyl-4-\{[(2(prop-2-enoyloxy)ethoxy] carbonyl\}benzoate (HETA) plays a role in the thermal, mechanical, and other properties of the resulting styrene-acrylic film, which was confirmed by the potential application of waste PET as decorative and protective coatings [32]. Jo et al. [33] proposed a model to explain the overall properties of polymer-modified jute fiber-reinforced cement slurry. Lu et al. [34] found that the hairy surface reduced the adsorption of polymer on the cement surface, leading to a small delay effect on cement hydration.

As the largest consumer of artificial cementing materials, ordinary Portland cement has high early strength, good frost resistance, dry shrinkage, and other advantages. However, Portland cement also possesses defects, such as a large number of pores after solidification and poor water and corrosion resistance [35]. To solve the abovementioned problems, research and development of polymer-modified cement-based materials have continued [36]. Adding polymers can improve the flexural strength, mechanical properties, permeability resistance, bioacid corrosion resistance, and chemical corrosion resistance of cement slurries [37]. The main emphasis of this paper is to study the properties of a modified cement slurry based on a degraded waste PET-modified styrene-acrylic emulsion.

\section{Materials and Equipment}

2.1. Preparation of the Modified Styrene-Acrylic Emulsion. As shown in Figure 1, the PET polyester waste is cleaned, pulverized, and reacted with ethylene glycol (EG) $(1: 2.5$ mass ratio) with a catalyst at $190^{\circ} \mathrm{C}$ for $2 \mathrm{~h}$ to fracture the polyester chains; the product is then separated and purified to obtain a low molecular weight ethylene terephthalate (BHET) intermediate. The chemical reaction route is shown in Figure 2.

First, the BHET PET degradation product, catalyst (ptoluenesulfonic acid), and dehydrating agent (4A molecular sieve) are put into a four-necked flask equipped with a thermometer, stirrer, and reflux condensing tube for the reaction, and the stirring speed is controlled at 400-500 r/ min. Second, the acrylic acid is added to the four-necked flask at the rate of 1 drop per minute through a constant pressure drop funnel, and the temperature is gradually increased to $70^{\circ} \mathrm{C}$. Then, the esterification reaction is carried out for $5 \mathrm{~h}$ at the same reaction temperature. Third, after the reaction is completed, the temperature is reduced to room temperature. The reaction mixture is added to a certain amount of toluene solvent, after which the mixture is refrigerated at $0^{\circ} \mathrm{C}$ for $24 \mathrm{~h}$. Finally, the condensed unreacted BHET solid is removed by filtration and then rotated to evaporate the filtrate. When the toluene solvent is removed, a yellow oily liquid remains. The yellow oily liquid is the functional monomer HETA, which is collected for later use.

The preparation of modified styrene-acrylic emulsions requires preemulsification and semicontinuous seed emulsion polymerization.

The preemulsification process occurs as follows: first, emulsifiers (sodium dodecyl sulfate (SDS) and OP-10 with a mass ratio of $1: 1$ ), ammonium persulfate (APS) initiators, and deionized water are added into the four-necked flask, stirred, and dispersed. Second, a certain amount of styrene, $n$-butyl acrylate, and functional monomer HETA are added and stirred rapidly, followed by preemulsification for $60 \mathrm{~min}$. Finally, the obtained emulsion is removed for later use.

The semicontinuous seed emulsion polymerization process occurs as follows: first, a certain amount of deionized water and the remaining SDS and OP-10 emulsifiers are added to a four-necked flask, stirred, and then heated. Second, when the temperature reaches $75^{\circ} \mathrm{C}$, the remaining APS initiator and the abovementioned emulsified monomer preemulsion mixture are placed in the constant pressure drop funnel. When the temperature reaches $80^{\circ} \mathrm{C}$, the preemulsion and residual initiator in the 


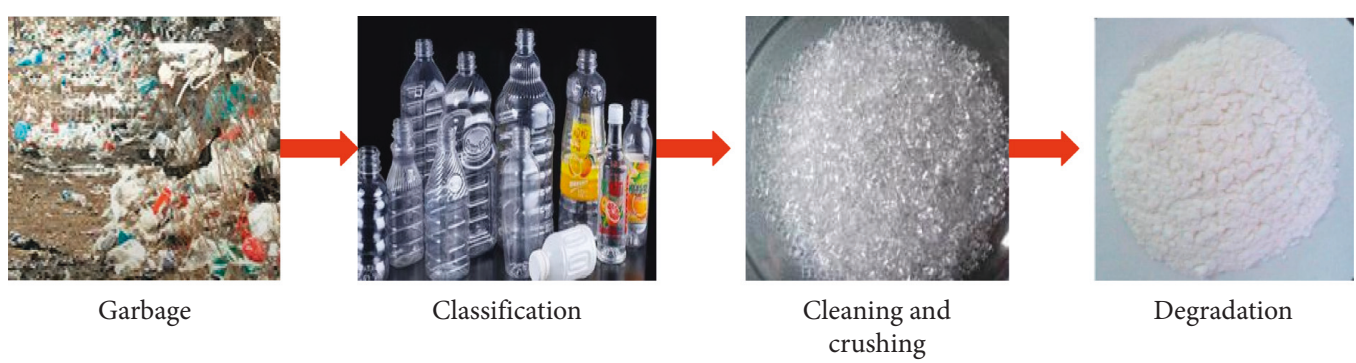

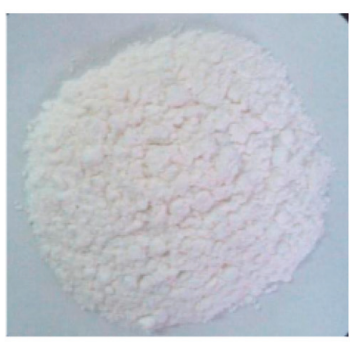

PET degradation products

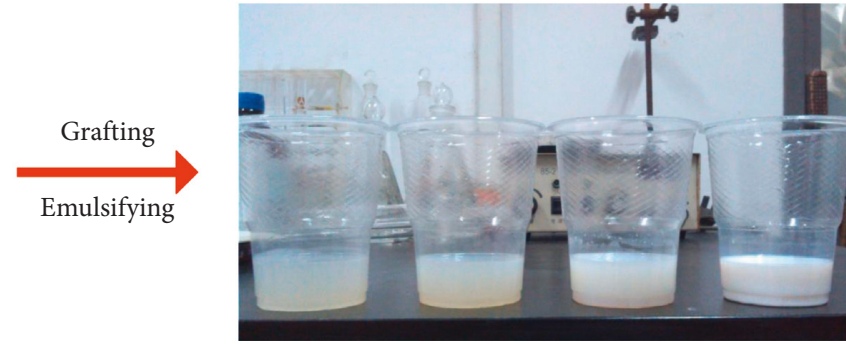

Regenerated emulsion

Figure 1: PET degradation process.
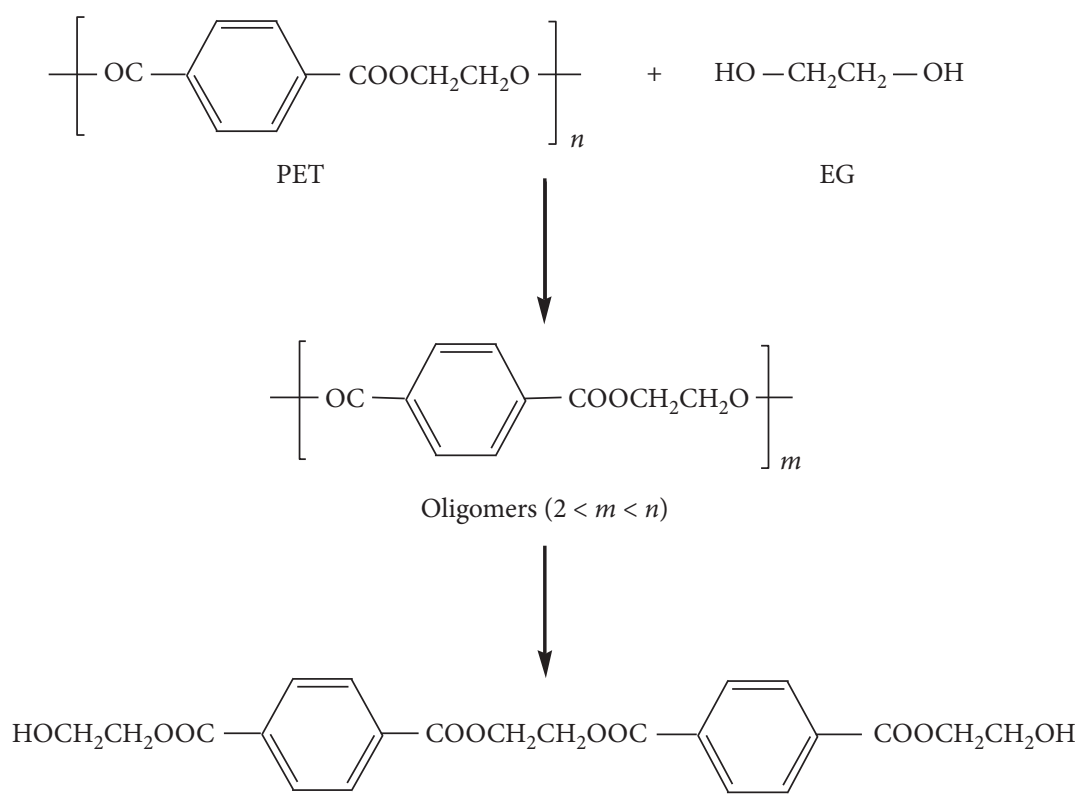

Dimer of BHET



FIGURE 2: Chemical reaction route for BHET.

constant pressure drop funnel are added to the reaction kettle at a uniform rate within $3 \mathrm{~h}$. After that, the temperature is kept at $80^{\circ} \mathrm{C}$ for an hour. Finally, the temperature is lowered to below $40^{\circ} \mathrm{C}$ after the insulation reaction completed. The $\mathrm{pH}$ value of the liquid is adjusted to 8.0 with ammonia, and then the modified styrene-acrylic emulsion is obtained by filtering out the material. The synthesis route is shown in Figure 3. 
<smiles>C=CC(=O)O</smiles><smiles>C=CC(=O)OCCOC(=O)c1ccc(C(=O)OCCO)cc1</smiles>

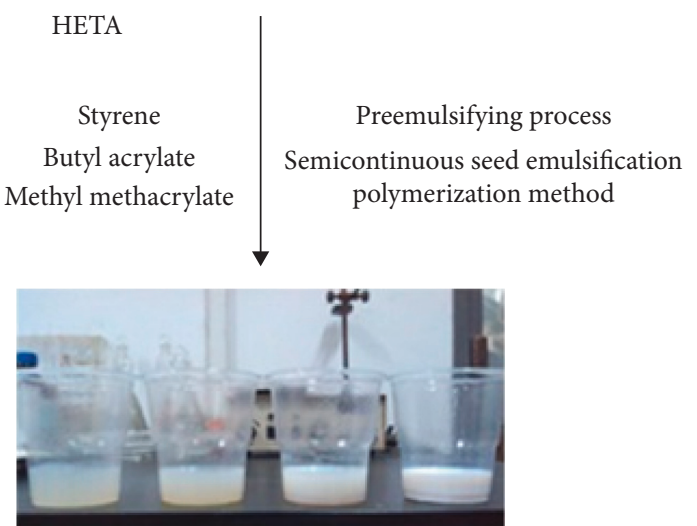

FIGURE 3: Synthesis route of the modified styrene-acrylic emulsion.

\subsection{Raw Material}

2.2.1. Cement. The cement used in this study is $42.5 \mathrm{R}$ ordinary Portland cement produced by Hunan Changsha Pingtang South Cement Co., LTD. The cement fineness is less than $5 \%$ of the sieve allowance through a $80 \mathrm{~ms}$ square hole sieve, and the performance meets the relevant requirements of the general Portland cement (GBl75-2007) standard. The main chemical and physical properties of the cement are shown in Table 1.

2.2.2. Modified Styrofoam Emulsion. The ratio of soft and hard monomer is $1: 1$, the dose of the emulsifier is $3.0 \%$ of the total monomer, the dose of the initiator is $0.6 \%$ of the total monomer, the $\mathrm{pH}$ value of the reaction system is $5-6$, the reaction temperature is $80^{\circ} \mathrm{C}$, and the dose of functional monomer is $25 \%$.

2.3. Equipment. The main devices applied are shown in Table 2.

\section{Methods}

3.1. Mix Proportions. Table 3 shows the mixing ratios of the modified styrene-acrylic emulsion and cement slurries, and the uniform water and cement mass ratio $(\mathrm{w} / \mathrm{c})$ is 0.5 . The effect of the polymer on the cement-based materials is studied by changing the content of the polymer.

The mixing of the cement slurries is carried out in accordance with the GB/T 1346-2011 test method for water consumption of standard cement consistency, setting time, and stability. The cement mixer is used for mixing, after which it is put into the test mold, vibrated and formed, and then stored in the curing box. Figure 4 shows the steps of curing and forming by mixing-modified styrene-acrylic emulsion cement slurry.

3.2. Curing System of the Cement Slurry Solidified Sample. After mixing, the cement slurry is placed into the curing box $\left(20 \pm 1^{\circ} \mathrm{C}\right)$ in the test mold $(40 \mathrm{~mm} \times 40 \mathrm{~mm} \times 160 \mathrm{~mm})$ and removed after curing at $95 \%$ humidity for $24 \mathrm{~h}$. After 
TABLE 1: The major chemical and physical properties of Portland cement.

\begin{tabular}{|c|c|c|c|c|c|c|c|}
\hline Chemical constituents & $\mathrm{SiO}_{2}$ & $\mathrm{Al}_{2} \mathrm{O}_{3}$ & $\mathrm{Fe}_{2} \mathrm{O}_{3}$ & $\mathrm{MgO}$ & $\mathrm{CaO}$ & $\mathrm{SO}_{3}$ & Loss on ignition \\
\hline Content (\%) & 23 & 7 & 5 & 3 & 56.8 & 3 & 2.2 \\
\hline Physical properties & Initial set & & Final set & & \multirow{2}{*}{\multicolumn{3}{|c|}{$\begin{array}{l}\text { 28-day compressive strength } \\
46.3 \mathrm{MPa}\end{array}$}} \\
\hline Test results & $155 \mathrm{~min}$ & & $235 \mathrm{~min}$ & & & & \\
\hline
\end{tabular}

TABLE 2: Instruments used in this study.

\begin{tabular}{lcc}
\hline Instrument name & Model & Manufacturer \\
\hline Cement mortar mixer & SJ-160B & Shenyang Julin Instrument Manufacturing Co., Ltd. \\
Cement standard consistency and setting time tester & GB/T 1346-2011 & Shanghai Luda Experimental Instrument Co., Ltd. \\
Manual screw testing machine & ALJ-02B & Fuzhou Epu Instrument Co., Ltd. \\
Pressure testing machine & C43.304 & Mechanical Testing Simulation \\
Scanning electron microscope & Hitachi S-4800 & Hitachi Ltd. \\
Mortar permeameter & SS-15 & Zhejiang Shangyu Xinguang Instrument Equipment \\
Electric folding tester & DKZ-5000 & Zhejiang Lu Da Experimental Instrument Co., Ltd. \\
\hline
\end{tabular}

TABLE 3: Mixture ratios of modified styrene-acrylic emulsion cement slurries.

\begin{tabular}{lcc}
\hline Serial number & Polymer-to-cement ratio $(\mathrm{p} / \mathrm{c})(\%)$ & Cement : polymer: water (quality of ratio) \\
\hline 1 & 0 & $1: 0: 0.5$ \\
2 & 2.5 & $1: 0.025: 0.5$ \\
3 & 5.0 & $1: 0.05: 0.5$ \\
4 & 7.5 & $1: 0.075: 0.5$ \\
5 & 10.0 & $1: 0.1: 0.5$ \\
\hline
\end{tabular}

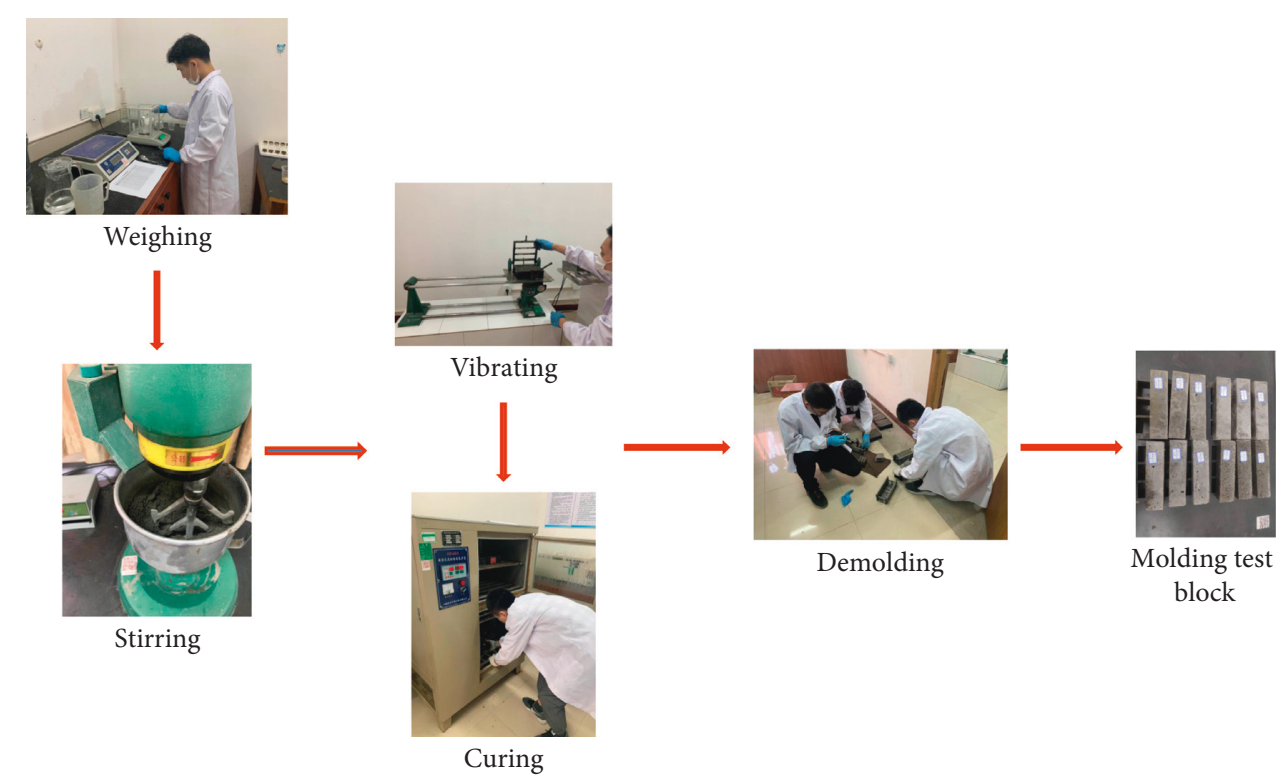

FIgURE 4: Mixing and curing of the modified styrene-acrylic emulsion cement slurry.

demolding, curing continues in the curing box for $7 \mathrm{~d}$. After that, it is cured for a total of $28 \mathrm{~d}$ at room temperature $(20 \pm 1)^{\circ} \mathrm{C}$ and a relative humidity no less than $65 \%$.

3.3. Determination of Water Consumption for Standard Consistency and Setting Time of the Cement Slurry. The mixing of modified cement slurry is carried out according to the GB/T1346-2011 test method for water consumption, setting time, and stability of standard cement consistency. The influence of the modified styrene-acrylic emulsion on the water consumption of standard consistency and the cement setting time of water consumption of standard consistency is measured by using a vicar apparatus; the setting time starts when the mixing water is added. The test blocks are maintained in the curing box. The temperature 
inside the box is $\left(20 \pm 3^{\circ} \mathrm{C}\right)$, the relative humidity is above $90 \%$, and a constant temperature and humidity inside the box are maintained. After the test block is stored in the curing box for $30 \mathrm{~min}$ after adding the mixing water, the first measurement occurs. The needle sinks into the cement slurry vertically and freely, and the reading occurs when the needle stops sinking. When the test needle sinks $2 \mathrm{~mm} \sim 3 \mathrm{~mm}$ from the bottom plate, the cement slurry has reached the initial setting state. When the subsidence does not exceed $0.5 \mathrm{~mm} \sim 1 \mathrm{~mm}$, the cement slurry reaches the final setting state. When the cement slurry is close to the setting time, it is measured every $5 \mathrm{~min}$, and when it is close to the final setting time, it is measured every $15 \mathrm{~min}$; the initial and final setting states are measured again immediately. The results of the two tests are the same, namely, the initial setting state or the final setting state. After the measurement, the test sample is immediately placed into the curing box. Figure 5 shows the vicar instrument.

\subsection{Determination of the Water Retention Rate of Cement} Slurry. According to the Chinese standard GBT3183-2003 for masonry cement, the influence of the modified styreneacrylic emulsion on the water retention rate of the cement slurry is determined. The water absorption treatment is carried out for the cement slurry with a fluidity of $180 \mathrm{~mm} \sim 190 \mathrm{~mm}$. The water retention rate of the cement slurry is the quantity of water retained in the cement slurry after water absorption treatment and is expressed as the mass percentage of the original water amount. The steps are as follows: weigh the test mold filled with cement slurry (inner diameter of $100 \mathrm{~mm}$ and internal effective depth of $25 \mathrm{~mm}$ ), which is accurate to $0.1 \mathrm{~g}$; cover the cement slurry surface with the filter screen, and put 8 weighed filter papers on the top of the filter screen; put a rigid bottom plate on the filter paper and invert the test die $180^{\circ}$ on a plane; invert the bottom of the test mold and put an iron weight of $2 \mathrm{~kg} ; 5 \mathrm{~min}$ later, take away the iron weight, and then put it back; and finally, remove the rigid bottom plate, filter paper, and mesh, and weigh the filter paper to an accuracy of $0.1 \mathrm{~g}$. Figure 6 shows the instrument used for determining the water retention rate of cement slurry. The water retention rate is calculated according to the following formula:

$$
Z=\frac{Y \times(W-U)}{1350+450+Y}
$$

where $U$ is the mass of the empty module in grams (g), $W$ is the test mold mass filled with cement slurry, in grams (g), and $Y$ is the amount of water used to prepare cement slurry of standard consistency, in grams (g).

The water retention rate $(R)$ is calculated according to the following equation:

$$
R=\frac{[Z-(X-V) \times 100]}{Z}
$$

where $V$ is the quality of the first 8 pieces of the filter paper before absorbing water in grams $(\mathrm{g}), X$ is the quality of 8 pieces of the filter paper after water absorption in grams $(\mathrm{g})$, and $Z$ is the amount of water in the cement slurry before absorption in grams $(\mathrm{g})$.

3.5. Determination of the Cement Slurry Impermeability. DL/T 5126-2001 test rules for polymer-modified cement mortar are used. An SS-15 mortar penetrator is used for the determination. The cement slurry is put into the test mold (height of $30 \mathrm{~mm}$, upper diameter of $70 \mathrm{~mm}$, and lower diameter of $80 \mathrm{~mm}$ ), and each group is composed of 6 pieces. The specimens are separated from the molds after curing for $24 \mathrm{~h}$ and then moved into the curing tank for curing until $28 \mathrm{~d}$. Specimens are aged, and then the specimens are removed from the water for demolding, cleaning, and air-drying. After that, the specimens are put into the mold of a permeameter and pressurized and sealed with paraffin. The initial water pressure is $0.2 \times 10^{4} \mathrm{~Pa}$, which increases to $1.47 \times 10^{4} \mathrm{~Pa}$ after $2 \mathrm{~h}$; a constant pressure is held for $6 \mathrm{~h}$. When the test stops, the test specimens are split into 5 points, and the height of seepage is measured with a ruler. Figure 7 shows the SS-15 mortar penetrator.

3.6. Determination of Flexural Strength in the Cement Slurry Curing Test. According to the ISO standard GB/T 176711999 , the cement slurry test block modified with the styreneacrylic emulsion with dimensions of $40 \mathrm{~mm} \times 40 \mathrm{~mm} \times 160 \mathrm{~mm}$ is placed on the DKZ-5000 electric bending test machine, and the load is vertically applied to the opposite side of the prism-shaped test block at the loading rate of $(50 \pm 10) \mathrm{N} / \mathrm{s}$ during the bending test, and then the fracture bending test of the specimen is stopped. The mean value of the flexural strength from a group of three prismatic test blocks was calculated, and if the strength value of one of the three prismatic test blocks exceeds the mean value by $10 \%$, then that data are removed, and the mean value from the remaining two blocks is reported as the flexural strength. Figure 8 shows the diagram of the test process. The flexural strength is calculated according to the following equation:

$$
R_{f}=\frac{1.5 F_{f} L}{b^{3}},
$$

where $F_{f}$ is the load applied to the middle of the prism when it is broken in newton $(\mathrm{N}), L$ is the distance between supporting cylinders in millimeters $(\mathrm{mm})$, and $B$ is the side length of a square section of the prism in millimeters (mm).

\subsection{Determination of Compressive Strength in the Cement} Slurry Curing Test. According to the ISO standard GB/T 17671-1999, the CXAW-300 compression testing machine is used to determine the compressive strength. The test block is placed on the test table, and the test is carried out on the side of the semiprism test block after the flexural test. The difference between the center of the half prism test block and the press platen is within $\pm 0.5 \mathrm{~mm}$, and the part of the prism test block exposed to the platen is approximately $10 \mathrm{~mm}$. 


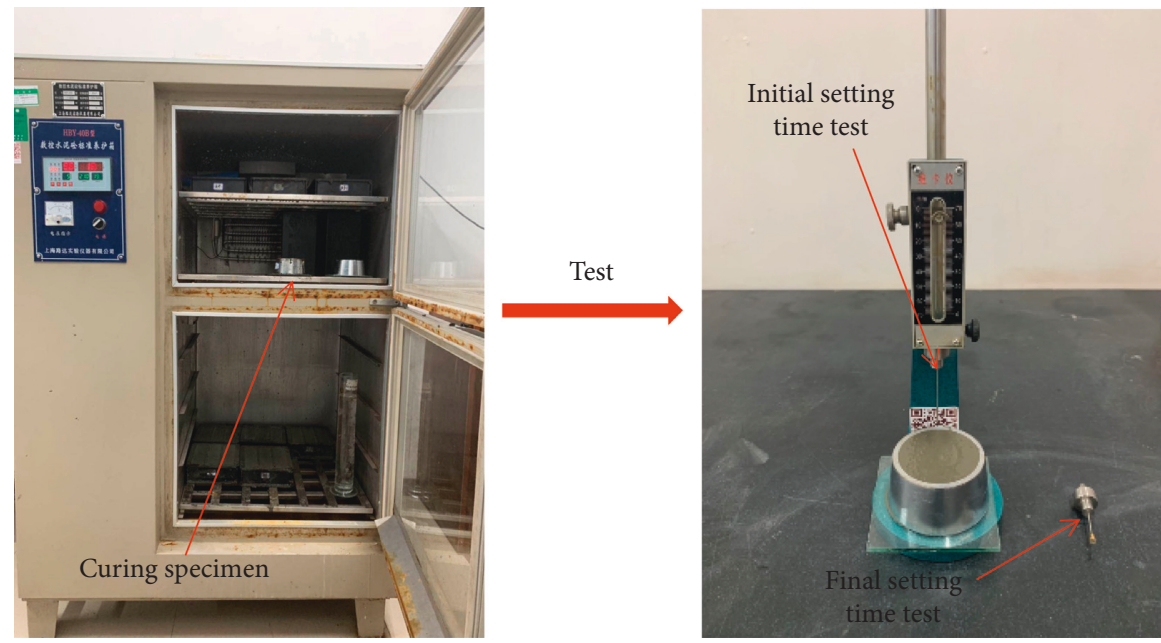

FIgURE 5: Determination of standard consistency and setting time of cement slurry.

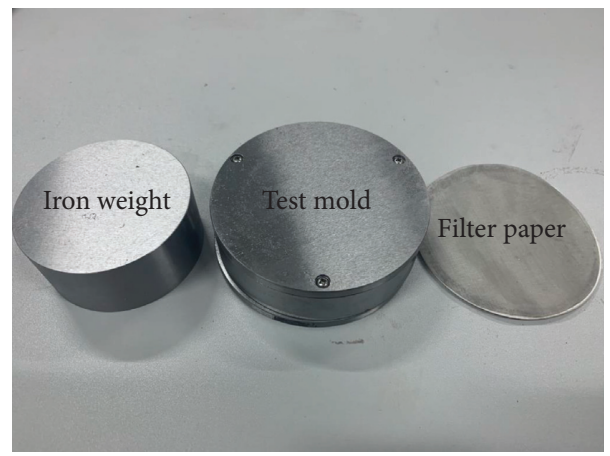

FiguRe 6: Measuring instrument for a water retention rate of cement slurry.
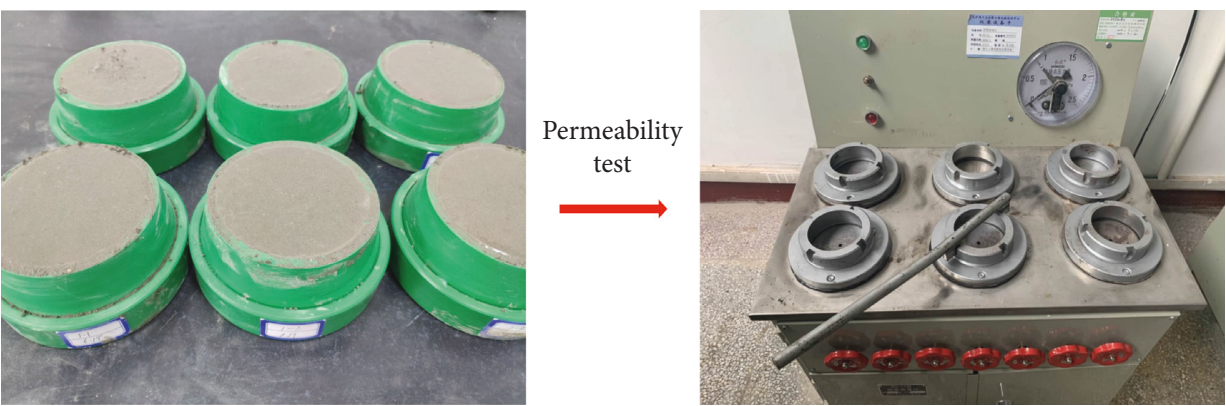

FIGURE 7: SS-15 mortar penetrator permeability test.

During the whole loading process, a loading speed of $2400 \pm 200 \mathrm{~N} / \mathrm{s}$ is used to conduct the compressive test uniformly. When the test block is destroyed, the compressive test stops. Six measured compressive strength values obtained from a set of three prismatic test blocks are used to calculate the arithmetic means of the test results. If one of the six measured values is $\pm 10 \%$ above the mean value of the six, the data result is excluded, and the mean value of the remaining five is used as the result. If more than $10 \%$ of the five measured values exceed the mean by $\pm 10 \%$, the results of this group are invalid. Figure 9 shows the test process. The compressive strength is calculated by the following equation:

$$
R_{c}=\frac{F_{c}}{A},
$$

where $F_{c}$ is the maximum load at failure time in newton (N) and $A$ is the area under compression in square millimeters $\left(\mathrm{mm}^{2}\right)\left(40 \mathrm{~mm} \times 40 \mathrm{~mm}=1600 \mathrm{~mm}^{2}\right)$.

3.8. Scanning Electron Microscopy (SEM) Observation of the Microstructure of the Solidified Cement Slurry. The $28 \mathrm{~d}$ solidified cement slurry test block is attached to the aluminum sample platform with conductive adhesive, and a 

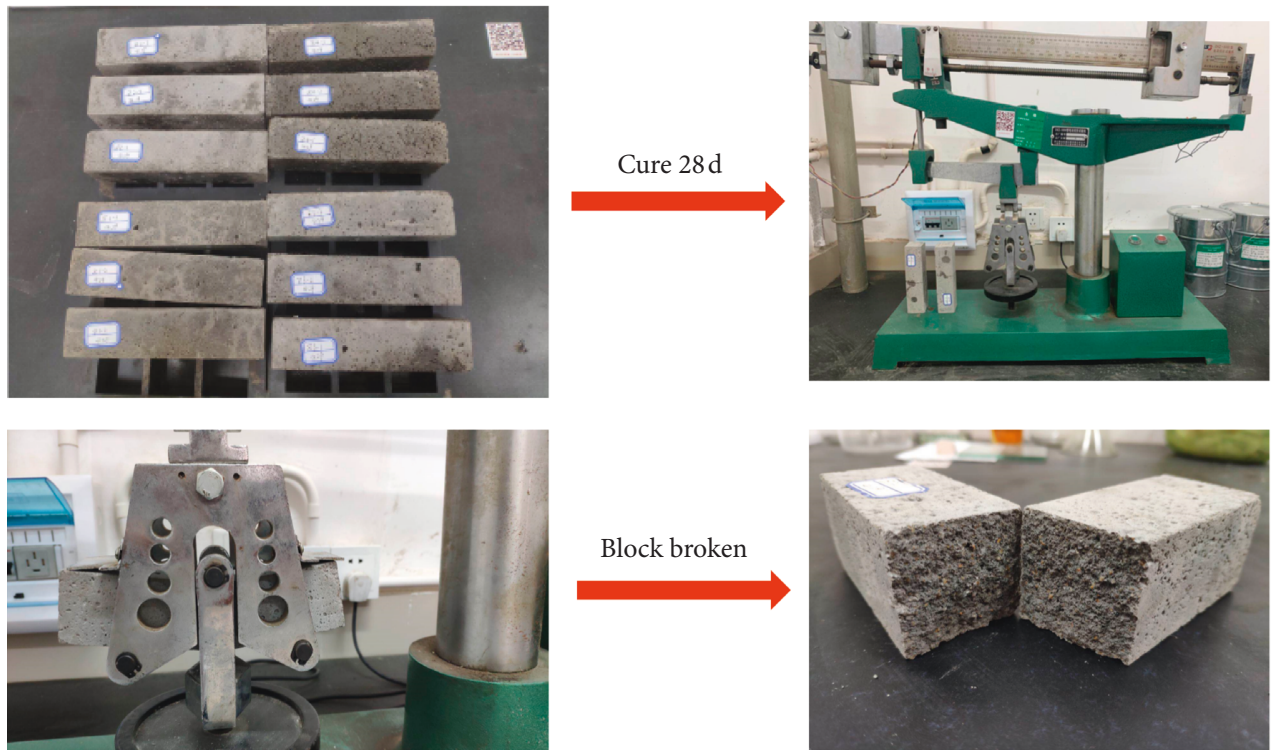

FIgURE 8: Flexural strength test of the solidified cement slurry.

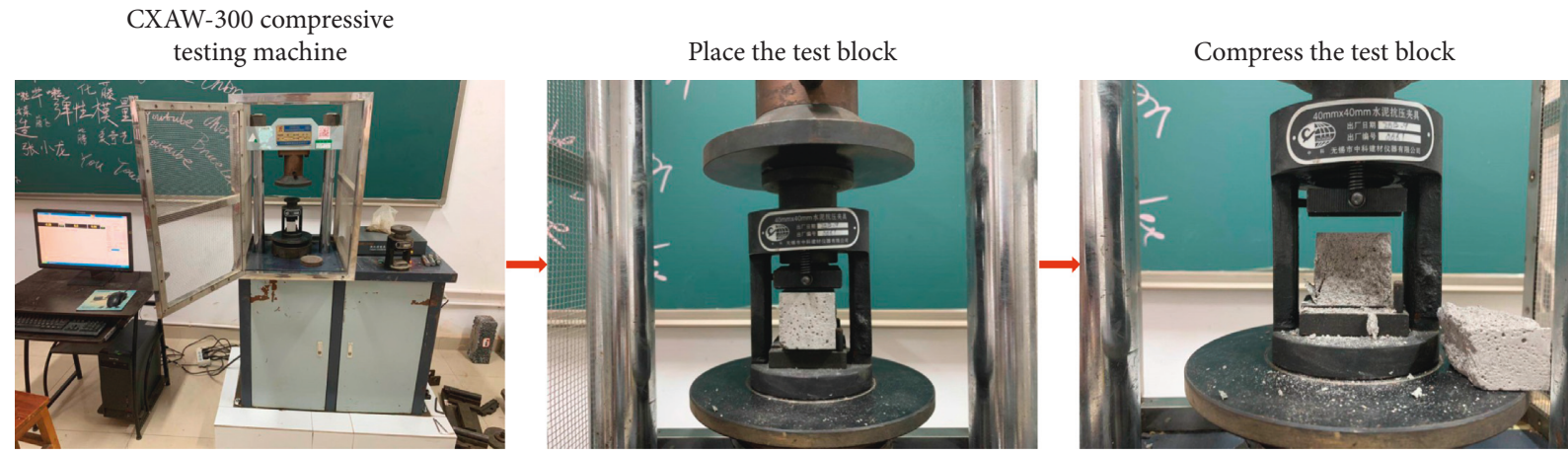

FIgURE 9: Compressive strength test of solidified cement slurry.

layer of the gold film is plated under high vacuum conditions. Then, a Hitachi s-4800 scanning electron microscope is used to observe the microstructure of the sample section.

\section{Results and Discussion}

4.1. Effect of the Modified Styrene-Acrylic Emulsion on the Water Consumption of the Cement Slurry with a Standard Consistency and Setting Time. Table 4 shows the mixing ratios of 5 kinds of emulsions in the cement slurry and their effects on the water reduction rate when the cement consistency reaches the standard value. With an increase in the amount of modified styrene-acrylic emulsion, the water consumption of standard consistency of the cement decreases. With increasing polymer content, the water reduction rate increases, but when the polymer content reaches $7.5 \%$, the water reduction effect slows down, as shown in Figure 10. When the content of the modified styrene-acrylic emulsion is $10.0 \%$, the water reduction rate reaches $36.0 \%$. On the one hand, due to the "bearing" effect of polymer particles and the effect of the introduced air, the viscosity of the cement slurry decreases and the fluidity increases. On the other hand, polymers with anion groups can be adsorbed on the surface of cement particles directionally and increase the zeta potential of the cement particles and disperse them, destroying the flocculation structure between the cement particles and therefore improving the flow of the cement slurry.

Figure 11 shows the influence of the modified styreneacrylic emulsion content on the setting time of cement slurry. As shown in Figure 11, the initial setting time and final setting time of the modified cement slurry increase with increasing polymer content. The slurry initial setting and final setting time increased with increasing dose of polymer emulsion because in the process of slurry mixing, the surface of cement particles is covered with the polymer, hindering the contact between the cement particles and water; thus, the formed hydration products cannot migrate well on the cement surface, so the cement hydration is delayed, which extends the setting time. In addition, due to the film-forming effect of the polymer emulsion, the extent of the hydration reaction of the water and cement inside the film is limited in a short time, leading to a reduction in free calcium oxide content, so the setting time is prolonged. At the same time, more hydroxyl groups on modified styrene-acrylic emulsion particles adsorb on the surface of the cement particles, 
TABLE 4: Mixture ratios and water reduction rates of emulsions in cement paste.

\begin{tabular}{lccc}
\hline Serial number & Polymer content (\%) & Water-cement ratio & Water reduction rate (\%) \\
\hline 1 & 0 & 0.250 & - \\
2 & 2.5 & 0.204 & 18.4 \\
3 & 5.0 & 0.189 & 24.4 \\
4 & 7.5 & 0.165 & 34.0 \\
5 & 10.0 & 0.160 & 36.0 \\
\hline
\end{tabular}

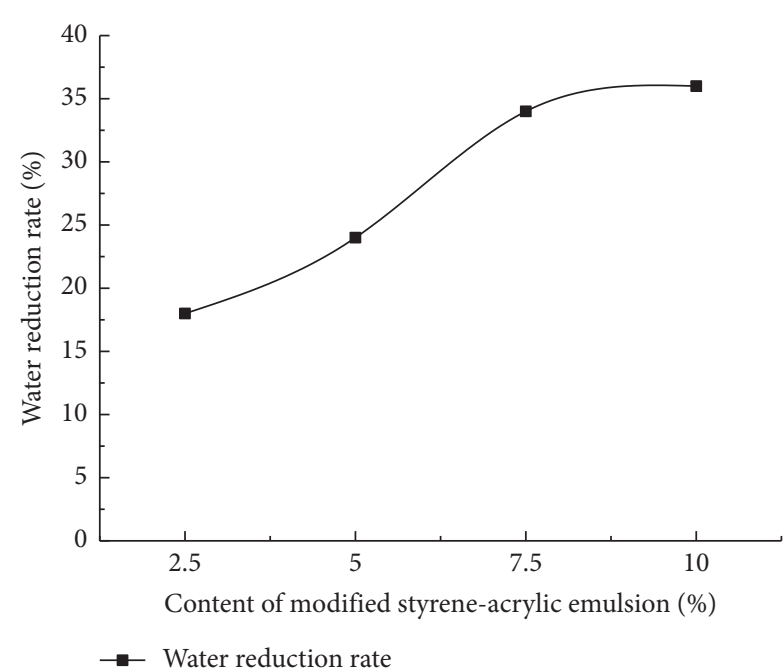

Figure 10: Influence of the modified styrene-acrylic emulsion content on the water reduction rate of the cement slurry.

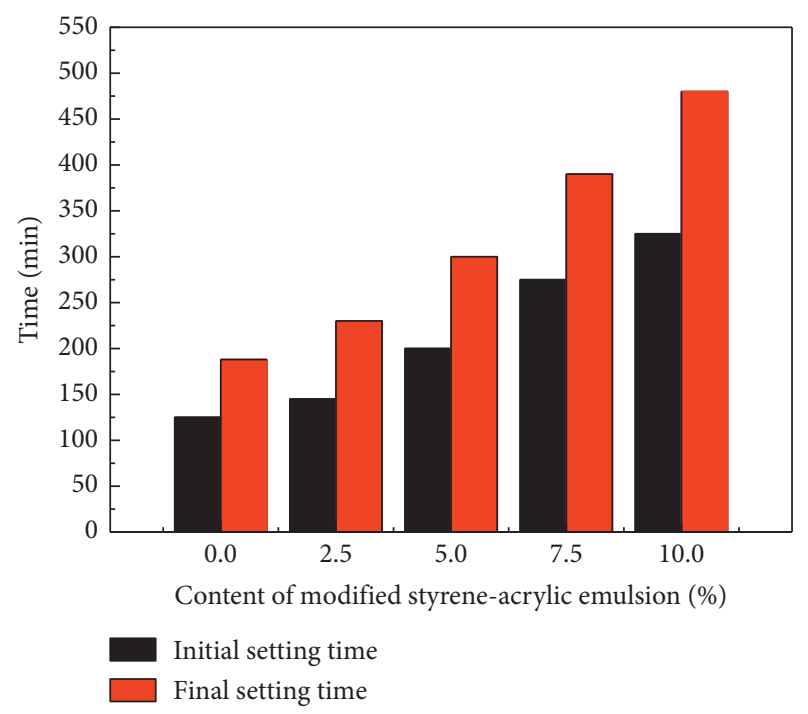

FIGURE 11: Influence of the emulsion content on the setting time of the cement slurry.

causing the cement particles to carry the same charge (negative charge), which disperses the cement particles and promotes cement hydration. The polymer emulsion has a retarding effect; the larger the dose, the more obvious the retarding effect. The film-forming effect of the polymer emulsion prohibits the cement from solidifying and setting in a short time. This film-forming phenomenon is more obvious with an increase in the polymerization ratio, which shows that the setting time is prolonged with an increase in the polymer ratio.

4.2. Effect of the Modified Styrene-Acrylic Emulsion on the Water Retention Rate of the Cement Slurry. The water retention of a cement slurry is a performance index to measure the stability of the cement slurry. If a cement slurry has poor water retention, it can easily lose water and affect the hydration of the cement, thereby affecting the construction and performance of the cement slurry. During transportation and storage, it is easy to produce bleeding and segregation. During construction, a cement slurry with poor water retention is easily absorbed by the base material, making the cement slurry too dry and thick and difficult to smooth. In addition, excessive loss of the cement slurry affects its setting and hardening and reduces its bonding and internal strength.

The water retention rate of a cement slurry quantifies the water retention in it. A high water retention rate indicates good water retention. A low water retention rate indicates poor water retention. Figure 12 shows the influence of the modified styrene-acrylic emulsion content on the water retention rate of the cement slurry. As shown in Figure 12, the water retention rate of the cement slurry increases with increasing content of the modified styrene-acrylic emulsion, and the water retention performance is significantly improved with increasing content of modified styrene-acrylic emulsion. The content of the styrene-acrylic emulsion increases by $2.5 \%$, and the average water retention rate increases by approximately 4\%; the water retention performance of cement slurry is therefore improved. This result is attributed to the hydrophilic colloid properties of the modified styrene-acrylic emulsion; the polymer film formed by the modified styrene-acrylic emulsion has a filling and sealing effect on the interconnecting capillary pores. This effect prevents water loss inside the cement slurry. Therefore, the water needed for cement hydration is retained in the cement slurry, making the cement hydrate more fully; at the same time, it can improve the bonding and internal strength of the cement slurry.

\subsection{Effect of the Modified Styrene-Acrylic Emulsion on the} Permeability Resistance of the Solidified Cement Slurry. Figure 13 shows the influence of the modified styrene-acrylic emulsion content on the impermeability of the solidified cement slurry test block. Figure 13 shows that the impermeability of the solidified cement slurry test block gradually increases with increasing polymer content and reaches the 


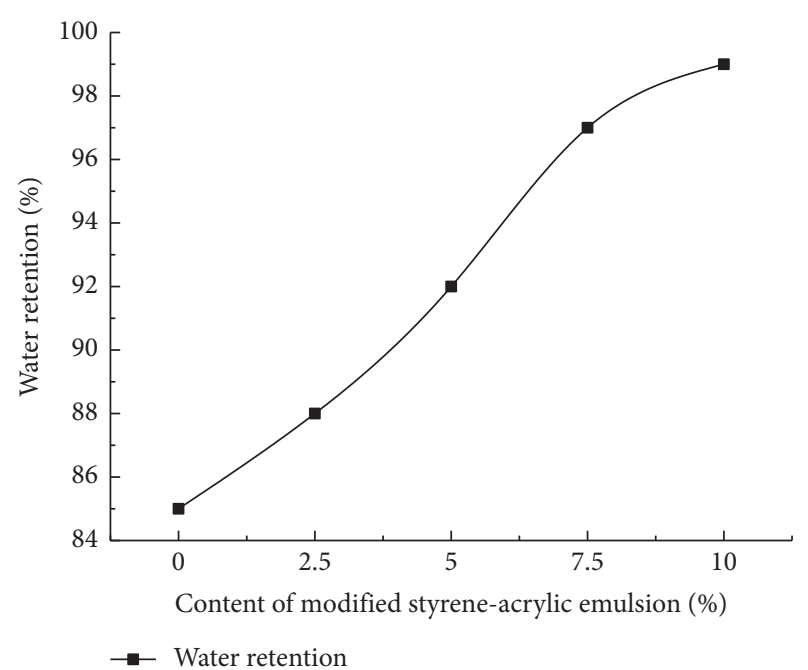

FIGURE 12: Influence of modified styrene-acrylic emulsion parameters on the water retention rate of the cement slurry.

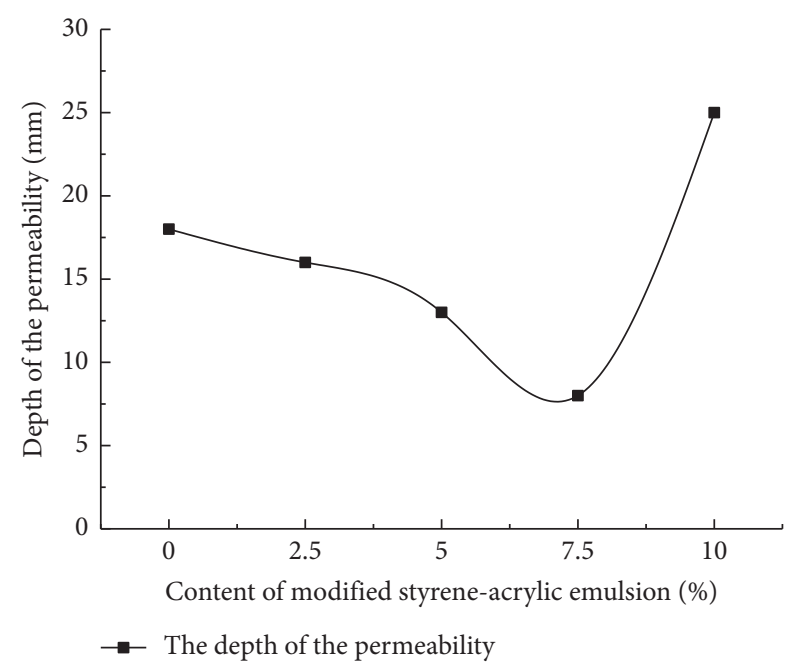

FIGURE 13: Influence of modified styrene-acrylic emulsion parameters on the impermeability of the cement slurry forming test block.

highest impermeability when the polymer content is $7.5 \%$. When the polymer content is $10.0 \%$, there is a substantial penetration. This is because at low polymer contents, when the polymer emulsion is mixed with the cement, latex particles begin to disperse into the cement. As a result of cement hydration, a cement gel gradually forms. As this gel structure develops and the water evaporates, a large number of polymer particles gather in the capillary pores of the cement gel structure, closing the capillary pores. At the same time, the evaporation rate is greatly reduced so that the cement continues to hydrate, increasing the compactness of the cement slurry. As the hydration and evaporation of the cement continue, the water in the capillary pores decreases even more, resulting in a continuous dense layer of polymer particles on the surface of the cement gel and an unhydrated cement particle mixture. Finally, the dense polymer particles form a continuous structure on the hydrated cement gel. On the contrary, because the modified styrene-acrylic emulsion modifier has the effect of reducing water, it can reduce the water-cement ratio of cement slurry. This is consistent with the rule that as ratio of the polymer cement increases the ratio of water to cement decreases. As a result, the number of large holes or connected holes in the solidified cement slurry decreases, which has a negative effect on the permeability resistance, so the permeability resistance is obviously improved. When the polymer content is $7.5 \%$, the solidified cement slurry shows good impermeability. When the polymer content is too high, the entrapment effect of the emulsion is obvious so that the pores of the solidified cement slurry test block increase in size and number. At the same time, the high polymer content increases the viscosity of the solidified cement slurry, and the emulsion is attached to the surface of particles, which hinders the hydration of cement. Therefore, when the polymer content is equal to $10.0 \%$, the impermeability of cement-hardened slurry decreases sharply, and the phenomenon of seepage occurs in the solidified cement slurry.

4.4. Effect of the Modified Styrene-Acrylic Emulsion on the Mechanical Properties of the Solidified Cement Slurry. Table 5 and Figures 14 and 15 show the influences of the modified styrene-acrylic emulsion on the flexural and compressive strengths of the solidified cement slurry test block. Table 5 and Figure 14 show that when the mixing amount is less than $7.5 \%$, the flexural strength of the three mature cement slurry samples increases. When the polymer content reaches $10.0 \%$, the flexural strength is similar to that of the solidified cement slurry without polymer content. As shown in Table 5 and Figure 15, the compressive strength of the three mature solidified cement slurry samples is lower than that of the solidified cement slurry without polymer as the polymer content increases. The reason why the flexural strength of the sample first increases and then decreases with increasing polymer content is that the modified styreneacrylic emulsion improves the interface of the modified cement slurry, and the modified styrene-acrylic emulsion competes with itself for the air entrainment. When the polymer content is low, the modified styrene-acrylic emulsion has a dominant effect on the interface improvement of the modified cement slurry. When the polymer content is high, the air entrainment of the modified styreneacrylic emulsion is dominant, so the flexural strength of the modified cement slurry is reduced. With increasing polymer content, the compressive strength decreases gradually. This is because the elastic modulus of the polymer is lower than that of the solidified cement slurry, and the compression of the complex polymer does not support rigidity. Therefore, the compressive strength of the modified cement slurry with the same water-cement ratio is lower than that of the solidified cement slurry without polymer mixing. However, as the age increases, the moisture in the emulsion volatilizes, and the polymer particles further condense, resulting in the formation of films with high strength and bonding. Therefore, the compressive strength still increases to some extent with age. 
TABLE 5: Influence of the modified styrene-acrylic emulsion on the flexural and compressive strengths of solidified cement slurry.

\begin{tabular}{lccccccc}
\hline $\begin{array}{l}\text { Polymer } \\
\begin{array}{l}\text { content } \\
(\%)\end{array}\end{array}$ & $\begin{array}{c}\text { Flexural } \\
\text { strength } \\
(\mathrm{MPa})\end{array}$ & $\begin{array}{c}\text { Compressive } \\
\text { strength (MPa) }\end{array}$ & $\begin{array}{c}\text { Flexural } \\
\text { strength } \\
(\mathrm{MPa})\end{array}$ & $\begin{array}{c}\text { Compressive } \\
\text { strength (MPa) }\end{array}$ & $\begin{array}{c}\text { Flexural } \\
\text { strength } \\
(\mathrm{MPa})\end{array}$ & $\begin{array}{c}\text { Compressive } \\
\text { strength (MPa) }\end{array}$ & $\begin{array}{c}\text { The ratio of compressive } \\
\text { strength to flexural strength } \\
\text { after 28 d }\end{array}$ \\
\hline 0 & 3.9 & 26.5 & 4.2 & 32.5 & 5.3 & 42.1 & 7.9 \\
2.5 & 4.0 & 25.9 & 4.4 & 30.8 & 5.5 & 38.6 & 7.0 \\
5.0 & 4.3 & 24.3 & 5.0 & 28.7 & 5.8 & 35.3 & 6.1 \\
7.5 & 4.8 & 20.8 & 5.6 & 25.8 & 6.5 & 30.2 & 4.6 \\
10.0 & 3.8 & 19.9 & 4.0 & 24.6 & 5.1 & 29.1 & 5.7 \\
\hline
\end{tabular}

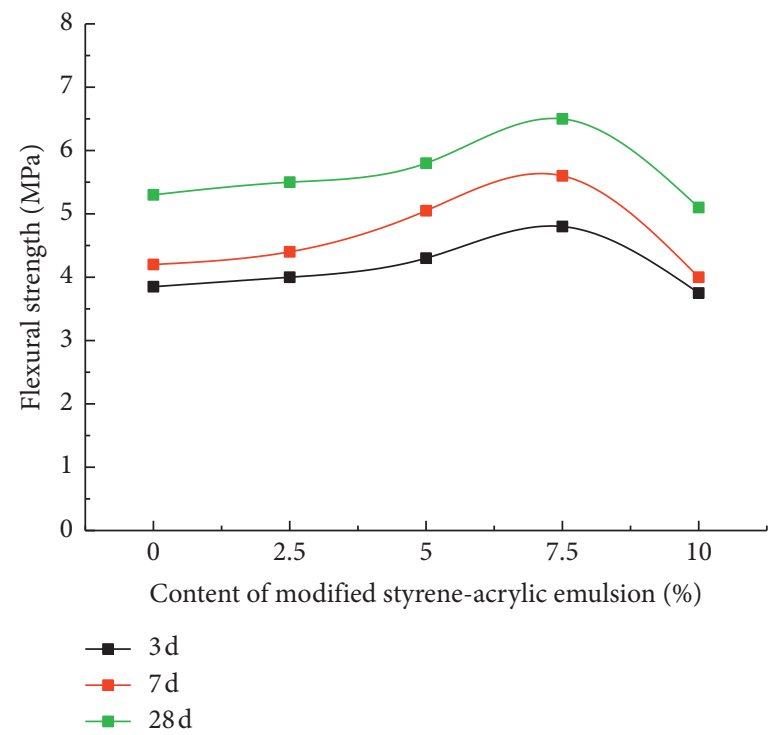

FIGURE 14: Influence of the modified styrene-acrylic emulsion on the flexural strength of the solidified cement slurry.

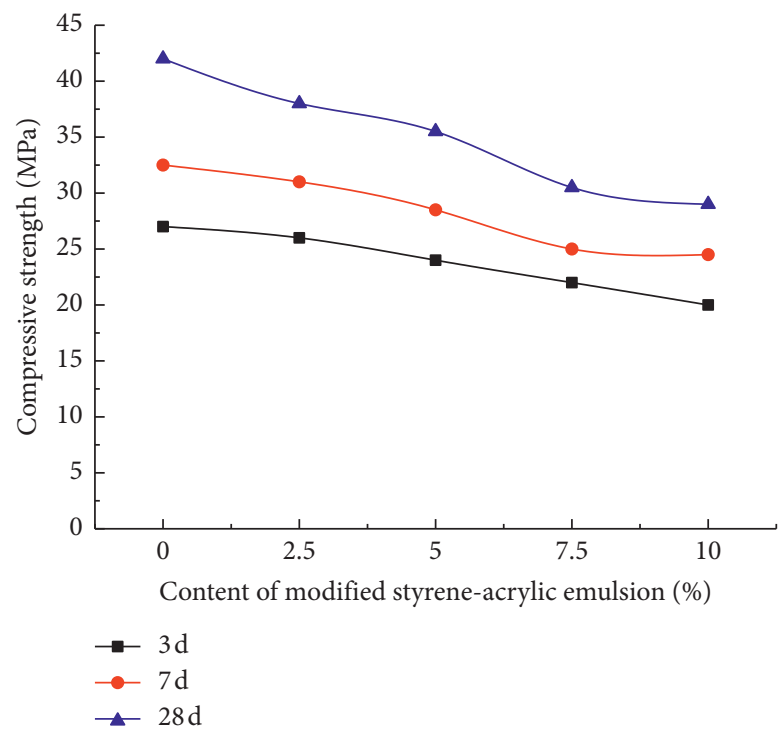

FIGURE 15: Influence of the modified styrene-acrylic emulsion on the compressive strength of the solidified cement slurry.

Figure 16 shows the influence of the modified styreneacrylic emulsion on the compression and flexural strength ratio after $28 \mathrm{~d}$ of standard curing for the modified cement slurry. With increasing polymer content, the compressive and flexural strength ratio of the modified cement slurry first decreases and then slightly increases, but it is still lower than that of the standard cement slurry. This shows that the toughness of the modified cement slurry increases and that 


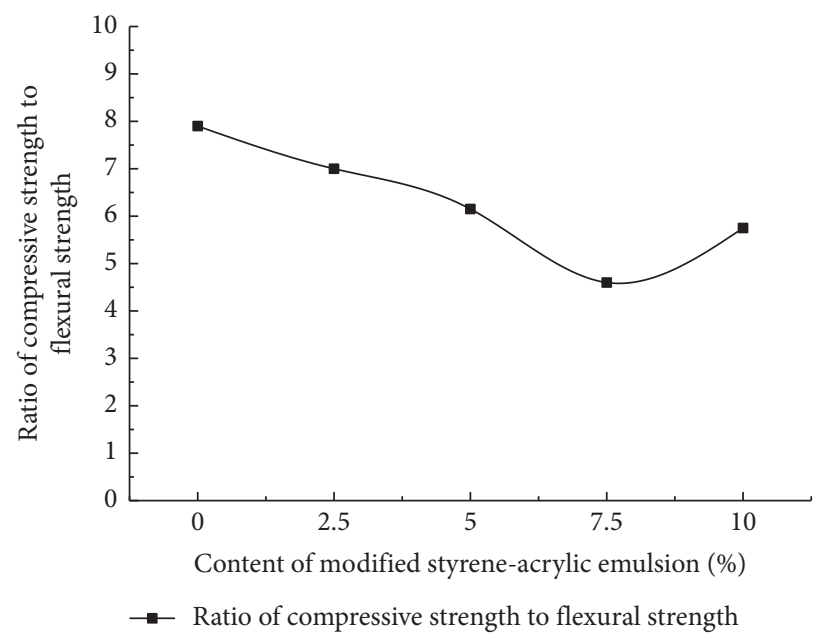

FIGURE 16: Influence of the modified styrene-acrylic emulsion content on the $28 \mathrm{~d}$ toughness of the modified cement slurry.

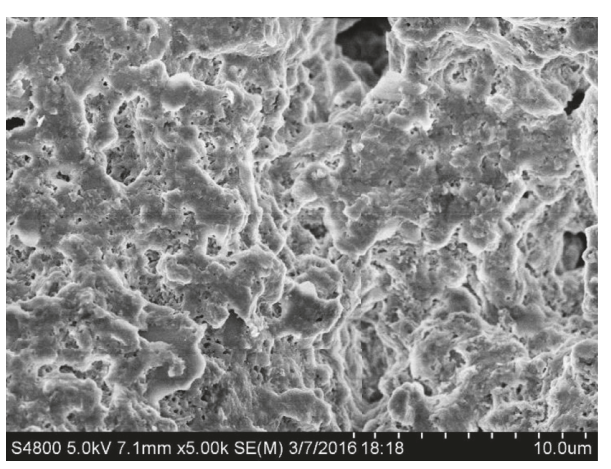

(a)

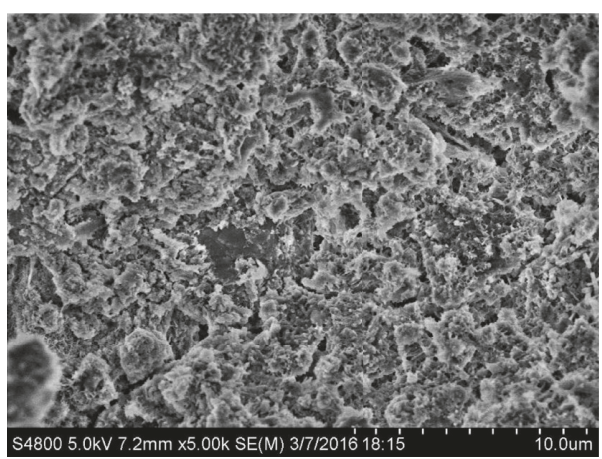

(c)

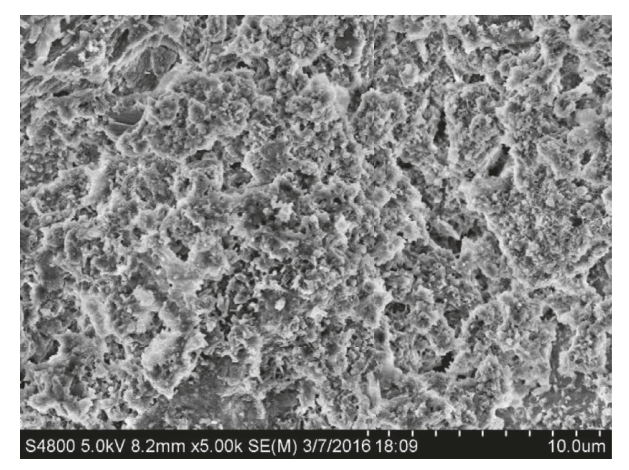

(b)

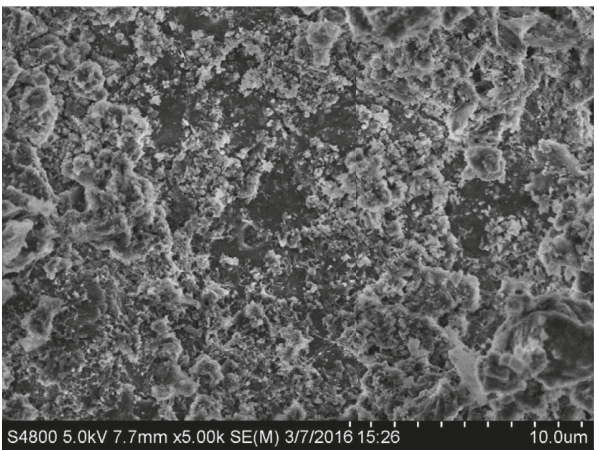

(d)

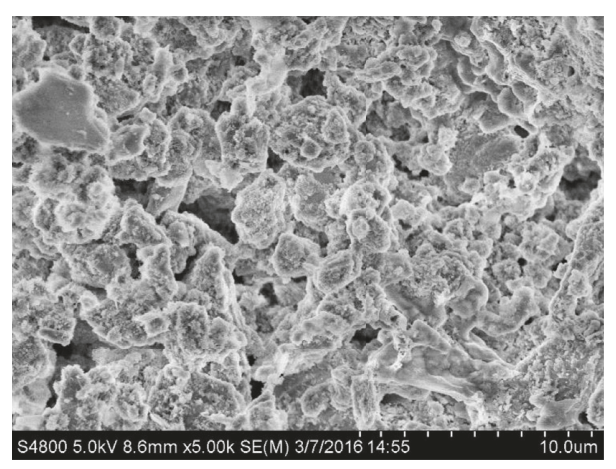

(e)

Figure 17: SEM of the solidified cement slurry test blocks. Polymer content: (a) $0 \%$, (b) 2.5\%, (c) 5\%, (d) 7.5\%, and (e) $10 \%$. 
the addition of a modified styrene-acrylic emulsion plays a role in toughening the cement slurry material.

4.5. Effect of the Modified Styrene-Acrylic Emulsion on the Microstructure of the Formed Cement Slurry. Figure 17(a) shows the SEM image of the section of the solidified cement slurry with a polymer content of $0 \%$, and the images in Figures 17(b)-1717(e) show the modified solidified cement slurry with polymer contents of $2.5 \%, 5.0 \%, 7.5 \%$, and $10.0 \%$, respectively.

As shown in Figure 17(a), a large number of pores and capillary channels exist in the interior of the solidified cement slurry with a polymer content of $0 \%$, and the pores are large, and the framework is loose and not dense. With increasing polymer content, the filling and sealing of the polymer film make the structure more compact and improve the porosity and loose framework of the solidified cement slurry. When the polymer content is $7.5 \%$, the density of the framework of the solidified cement slurry is excellent. When the polymer content continues to increase, the bleeding air effect of the emulsion is obvious so that the cement slurry pores become increasingly loose and empty. According to the research of Chandra [38], in addition to filling the polymer and sealing the film, $-\mathrm{OH}$ active groups in the modified styrene-acrylic emulsions can form ionic bonds with $\mathrm{Ca}^{2+}$ positive ions in cement. The network structure formed by bridging ionic bond macromolecular systems can also enhance the compactness of the structure and improve the performance of cement-based composites.

\section{Conclusions}

The modified styrene-acrylic emulsion can significantly reduce the water consumption to achieve a standard consistency and has water reduction capacity. When the polymer content is $10 \%$, the water reduction rate is $36 \%$. In addition, the modified styrene-acrylic emulsion has an effect on the initial setting time and final setting time of the cement paste. With the increase in polymer content, the initial setting time and final setting time of the cement paste slow down, indicating that the modified styrene-acrylic emulsion improves the physical properties of cement paste.

The modified styrene-acrylic emulsion significantly improves the water retention performance of the cement slurry. When the modified styrene-acrylic emulsion content is less than $7.5 \%$, it has a great impact on the water retention performance of cement slurry. Among the contents considered in this study, when the modified styrene-acrylic emulsion content is $7.5 \%$, the seepage height of the sample reaches its minimum; when the content is $10 \%$, the impermeability of the solidified cement slurry decreases sharply, and the seepage height of the sample increases sharply. The mixing amount of the modified styrene-acrylic emulsion should be controlled within $7.5 \%$, where the water retention effect of the cement slurry is the best of the contents considered in this study.

The influence of the modified styrene-acrylic emulsion on the mechanical properties of the modified cement slurry with different curing ages is studied. The results show that when less than $7.5 \%$ of the modified styrene-acrylic emulsion is mixed, the flexural strength of the cement slurry at three ages increases, and when $10 \%$ of the modified styreneacrylic emulsion is mixed, the flexural strength is similar to that of the pure cement slurry (cement slurry without the polymer). The compressive strength of cement slurry mixed with the modified styrene-acrylic emulsion at three ages is lower than that of the pure cement slurry. The reduction of the compression ratio indicates that the modified styreneacrylic emulsion has a certain toughening effect on cement slurries. In light of comprehensive economic factors and other properties, controlling the polymer content to within $7.5 \%$ can obtain an excellent performing cement slurry.

According to SEM observations, the modified styreneacrylic emulsion can improve the bond strength between cement particles and the performance of cement slurry.

\section{Data Availability}

The data used to support the findings of this study are included within the article.

\section{Conflicts of Interest}

The authors declare that there are no conflicts of interest regarding the publication of this paper.

\section{Acknowledgments}

This work was supported by the Hunan Province Science and Technology Project of China (2014FJ3076). The authors are also grateful to their partner Sinohydro Bureau 8 Co., LTD, in China.

\section{References}

[1] C. Lei, S. Yue, S. Wang et al., "Study on the degradation mechanism of PET by polyols," Journal of Natural Sciences of Harbin Normal University, vol. 30, no. 4, pp. 75-79, 2014, in Chinese.

[2] M. Ghaemy and K. Mossaddegh, "Depolymerisation of poly(ethylene terephthalate) fibre wastes using ethylene glycol," Polymer Degradation and Stability, vol. 90, no. 3, pp. 570-576, 2005.

[3] C. Wang, "Study on the degradation of PET polyester catalyzed by alkaline ionic liquid," Master's thesis, Harbin Normal University, Harbin, China, 2013, in Chinese.

[4] D. S. Achilias, H. H. Redhwi, M. N. Siddiqui, A. K. Nikolaidis, D. N. Bikiaris, and G. P. Karayannidis, "Glycolytic depolymerization of PET waste in a microwave reactor," Journal of Applied Polymer Science, vol. 118, no. 5, pp. 3066-3073, 2010.

[5] R. López-Fonseca, I. Duque-Ingunza, B. de Rivas, S. Arnaiz, and J. I. Gutiérrez-Ortiz, "Chemical recycling of post-consumer PET wastes by glycolysis in the presence of metal salts," Polymer Degradation and Stability, vol. 95, no. 6, pp. 10221028, 2010.

[6] G. P. Karayannidis and D. S. Achilias, "Chemical recycling of poly(ethylene terephthalate)," Macromolecular Materials and Engineering, vol. 292, no. 2, pp. 128-146, 2007. 
[7] S. R. Shukla, A. M. Harad, and L. S. Jawale, "Chemical recycling of PET waste into hydrophobic textile dyestuffs," Polymer Degradation and Stability, vol. 94, no. 4, pp. 604-609, 2009.

[8] S. R. Shukla, A. M. Harad, and L. S. Jawale, "Recycling of waste PET into useful textile auxiliaries," Waste Management, vol. 28 , no. 1 , pp. 51-56, 2008.

[9] M. S. Farahat and D. E. Nikles, "On the UV curability and mechanical properties of novel binder systems derived from poly(ethylene terephthalate) (PET) waste for solventless magnetic tape manufacturing. 2. Methacrylated oligoesters," Macromolecular Materials and Engineering, vol. 287, no. 5, pp. 353-362, 2002.

[10] A. K. Khan and S. Chandra, "Surface coatings from polyester waste," Paintindia, vol. 45, no. 8, p. 35, 1995.

[11] O. Saravari, B. Vessabutr, and V. Pimpan, "Synthesis of urethane oils from waste poly(ethylene terephthalate) bottles," Journal of Applied Polymer Science, vol. 88, no. 92, pp. 3040-3045, 1966.

[12] M. E. Tawfik, "Preparation and characterization of waterextended polyester based on recycled poly(ethylene terephthalate)," Journal of Applied Polymer Science, vol. 89, no. 13, pp. 3693-3699, 2003.

[13] M. E. Tawfik and S. B. Eskander, "Polymer concrete from marble wastes and recycled poly(ethylene terephthalate)," Journal of Elastomers \& Plastics, vol. 38, no. 1, pp. 65-79, 2006.

[14] J. C. O. Villanova, E. Ayres, M. O. Reis, and R. L. Oréfice, "Acrylic polymers derived from high solid emulsions as excipients to pharmaceutical applications: synthesis and characterization," Polymer Bulletin, vol. 68, no. 4, pp. 931-948, 2012.

[15] J. M. Ramos-Fernández, C. Guillem, A. Lopez-Buendía, M. Paulis, and J. M. Asua, "Synthesis of poly-(BA-co-MMA) latexes filled with $\mathrm{SiO}_{2}$ for coating in construction applications," Progress in Organic Coatings, vol. 72, no. 3, pp. 438442, 2011.

[16] X. Zhang, Macromolecular Chemistry, Chemical Industry Press, Beijing, China, 2013, in Chinese.

[17] J. S. Hubby, Solution Polymerization Process, US Patent 4271060, 1981.

[18] E. Vivaldo-Lima, P. E. Wood, A. E. Hamielec, and A. Penlidis, "An updated review on suspension polymerization," Industrial \& Engineering Chemistry Research, vol. 36, no. 4, pp. 939-965, 1997.

[19] H. Zhu, "Preparation and characterization of epoxy modified styrene-acrylic emulsion and its coatings," Master's thesis, Jiangsu University of Science and Technology, Zhenjiang, China, 2011, in Chinese.

[20] L. K. Aggarwal, P. C. Thapliyal, and S. R. Karade, "Properties of polymer-modified mortars using epoxy and acrylic emulsions," Construction and Building Materials, vol. 21, no. 2, pp. 379-383, 2007.

[21] B. Lessard, S. C. Schmidt, and M. Marić, "Styrene/acrylic acid random copolymers synthesized by nitroxide-mediated polymerization: effect of free nitroxide on kinetics and copolymer composition," Macromolecules, vol. 41, no. 10, pp. 3446-3454, 2008.

[22] R. S. Tiğlı and V. Evren, "Synthesis and characterization of pure poly(acrylate) latexes," Progress in Organic Coatings, vol. 52, no. 2, pp. 144-150, 2005.

[23] R. A. Brown, R. G. Coogan, D. G. Fortier, M. S. Reeve, and J. D. Rega, "Comparing and contrasting the properties of urethane/acrylic hybrids with those of corresponding blends of urethane dispersions and acrylic emulsions," Progress in Organic Coatings, vol. 52, no. 1, pp. 73-84, 2005.
[24] Y. Cui, Q. Zhang, H. Duan et al., "Study on crosslinking reaction between waterborne polyurethane and acrylate emulsion," The Plastics Industry, vol. 30, no. 1, pp. 10-12, 2002, in Chinese.

[25] C. Ruitao, D. Wang, J. Lan et al., "Preparation of hydrophilic polyurethane/styrene-acrylate emulsion and their application in surface sizing," China Synthetic Rubber Industry, vol. 32, no. 6, pp. 485-489, 2009.

[26] C. Zhang, X. Zhang, J. Dai, and C. Bai, "Synthesis and properties of PDMS modified waterborne polyurethaneacrylic hybrid emulsion by solvent-free method," Progress in Organic Coatings, vol. 63, no. 2, pp. 238-244, 2008.

[27] K. C. You, L. D. Shan, K. X. Zheng, and X. L. Zhu, "Study on the preparation and properties of styrene-butyl acrylate-silicone copolymer latices," Journal of Applied Polymer Science, vol. 82, no. 13, pp. 3194-3200, 2001.

[28] Z. Wang, Y. Cheng, D. Dong et al., "Modification effect of organosilicon - fluorine on properties and coating properties of the styrene-acrylic emulsion," Chemistry and Bonding, vol. 32, no. 3, pp. 31-34, 2010, in Chinese.

[29] H. Wang, F. Yang, A. Zhu, T. Lu, F. Kong, and L. Ji, "Preparation and reticulation of styrene acrylic/epoxy complex latex," Polymer Bulletin, vol. 71, no. 6, pp. 1523-1537, 2014.

[30] J. T. K. Woo and A. Toman, "Water-based epoxy-acrylic graft copolymer," Progress in Organic Coatings, vol. 21, no. 93, pp. 371-385, 1993.

[31] S. Li, "Preparation and application of antiseptic emulsion and self-crosslinking functional emulsion," Master's thesis, $\mathrm{Hu}-$ nan Normal University, Changsha, China, 2012, in Chinese.

[32] C. Ji, J. Fang, J. Wang, P. Fang, and S. Li, "Influence of modified PET waste on synthesis and properties of styreneacrylic emulsion," Polymer Science Series B, vol. 58, no. 5, pp. 610-618, 2016.

[33] B.-W. Jo, S. Chakraborty, and Y. S. Lee, "Hydration study of the polymer modified jute fibre reinforced cement paste using analytical techniques," Construction and Building Materials, vol. 101, pp. 166-173, 2015.

[34] Z. Lu, X. Kong, C. Zhang et al., "Effect of surface modification of colloidal particles in polymer latexes on cement hydration," Construction and Building Materials, vol. 155, pp. 1147-1157, 2017.

[35] B. Ren and X. Cui, "Effect of polymer emulsion on mechanical properties and microstructure of cement mortar," Commercial Concrete, vol. 6, pp. 31-37, 2013, in Chinese.

[36] Y. Chen and X. Pu, "Hydration characteristics of sodium sulfate slag cement system," Journal of Wuhan University of Technology-Materials Science Edition, vol. 16, no. 4, pp. 45-47, 2001.

[37] H. Diab, L. B. Dor, C. Heitner-Wirguin, and D. Bonen, "The porosity and compressive strength of polymer-cement," $\mathrm{Ce}$ ment and Concrete Research, vol. 15, no. 6, pp. 1061-1067, 1985.

[38] S. Chandra and P. Flodin, "Interactions of polymers and organic admixtures on portland cement hydration," Cement and Concrete Research, vol. 17, no. 6, pp. 875-890, 1987. 


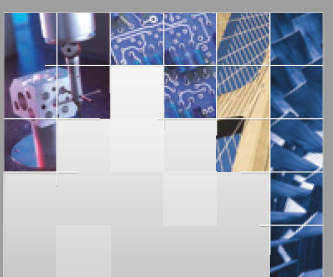

\section{Enfincering}
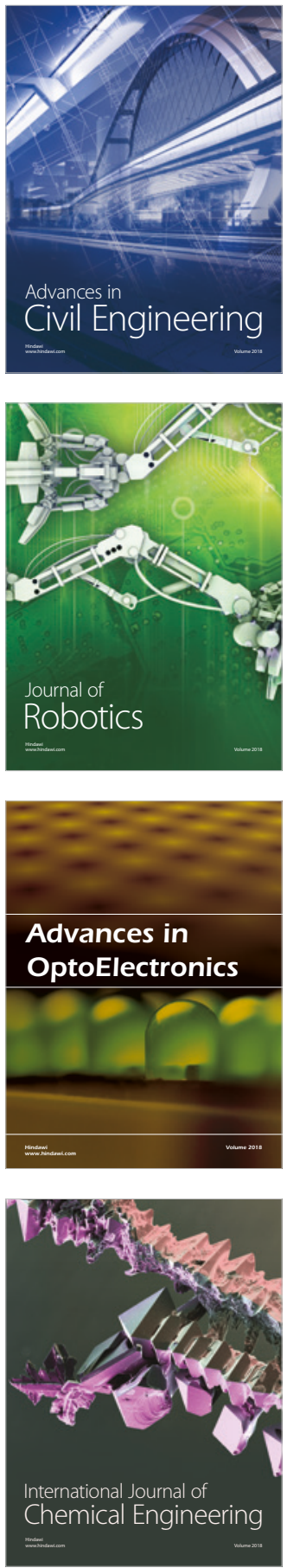

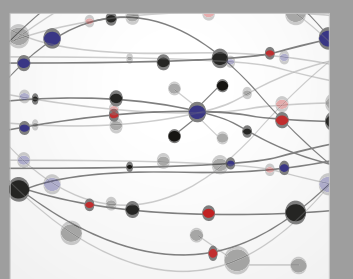

\section{Rotating \\ Machinery}

The Scientific World Journal

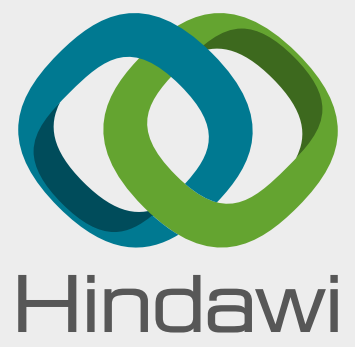

Submit your manuscripts at

www.hindawi.com
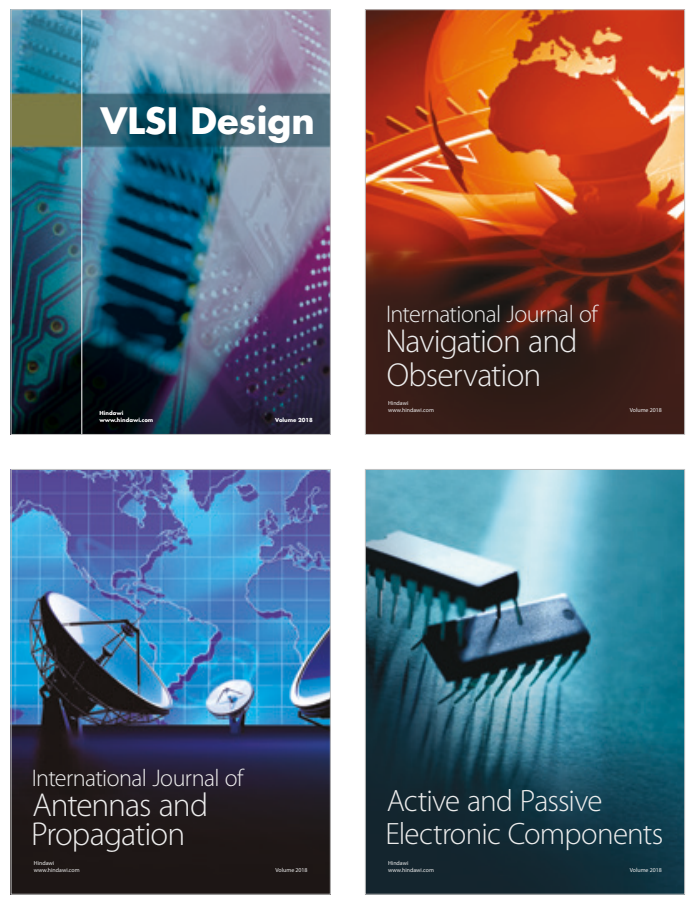


\section{Advances \\ Multimedia}
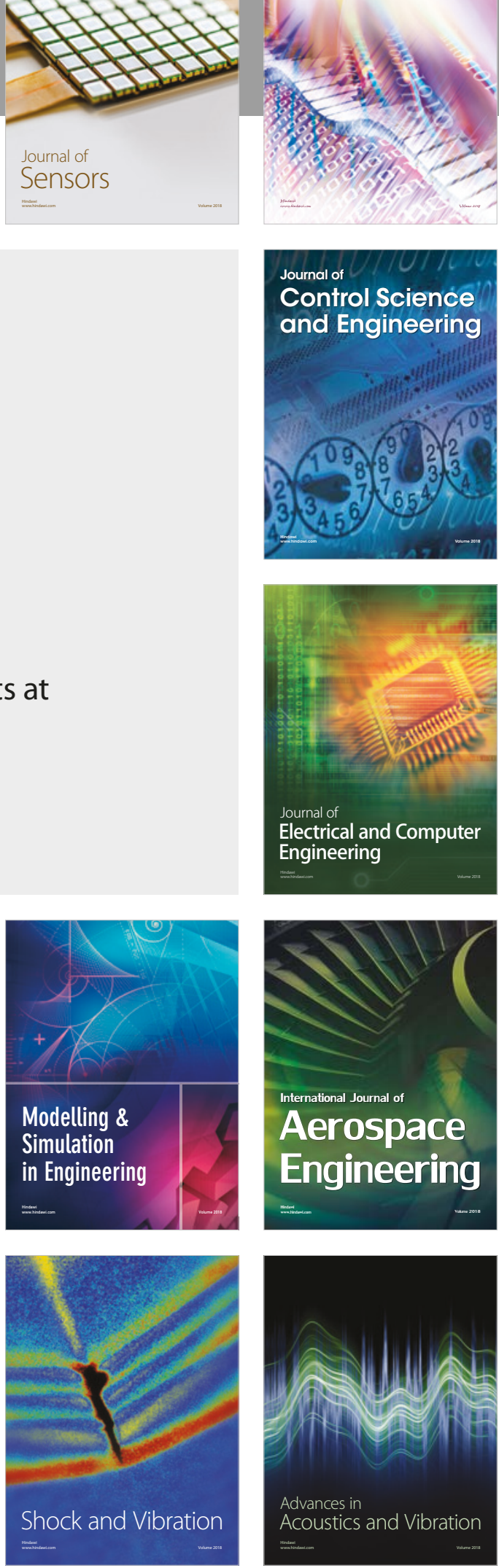